\title{
An Applied Study to Image-G Transmission in Chinese Literary on Gestalt Perception Laws
}

\author{
Chong Su1,2 \\ ${ }^{1}$ Southwest University, Chongqing, China \\ ${ }^{2}$ Southwest Petroleum University, Chengdu, China \\ Email: 1336380317@qq.com
}

How to cite this paper: $\mathrm{Su}, \mathrm{C}$. (2017). An Applied Study to Image-G Transmission in Chinese Literary on Gestalt Perception Laws. Open Journal of Modern Linguistics, 7,272-289.

https://doi.org/10.4236/ojml.2017.76020

Received: November 29, 2017

Accepted: December 25, 2017

Published: December 28, 2017

Copyright (C) 2017 by author and Scientific Research Publishing Inc. This work is licensed under the Creative Commons Attribution International License (CC BY 4.0).

http://creativecommons.org/licenses/by/4.0/

\begin{abstract}
As a significant school in contemporary cognitive science, gestalt psychology provides theoretical framework for the multidimensional research on cognitive study. The organization of gestalt perceptual principle provides conceptual model to the psychophysical field and has an overwhelming impact on various gestalt perception laws. Gestalt perception laws' major theoretical perspectives make them as the methodological principle of gestalt image (image-G) study in cognitive translation which could be viewed from both mental and conceptual perspectives. By employing gestalt perception laws, the paper focuses on making a tentative and exploratory study of gestalt image transmission in Chinese literary translation and thus aims to discover translators' conceptual mental experience of image- $G$ transmission in Chinese literary translation through their cognitive processing.
\end{abstract}

\section{Keywords}

Gestalt Psychology, Gestalt Perception Laws, Image-G Transmission, Chinese Literary Translation

\section{Introduction}

In the past research, perceptual theory was under the upper hand over the structuralist propositions of which a whole consists of parts and the parts constitute a whole. They proposed that complicated perceptual phenomena were formulated from particles of basic color perception and consciousness and integrated by associations owing to the proximity of spatial and temporal nature (Pinna, 2009). Those kinds of research were not well aware that the organization of perceptual phenomena is a sensory fact owing to they are under the influence of and constrained by the empirical preconception. Gestalt psychology scholars 
turn down such kind of suppositions, indicating that perception is intimately interconnected and explicable only by reference to the whole and organized on account of reciprocal effect between structure and latent cognitive operation. Gestalt perception is a designation appointed to numerous perceptual phenomena and conceptual principles correlated with the school of gestalt psychology. Its prodigiously significant theoretical essence is closely related with perceptual organization, involving inherent and essential features of connection between parts and wholes and how the organization of parts and wholes are determined by human sensory experience and cognitive processing. The issue of gestalt perceptual grouping in sensory fields was put forward by Wertheimer (1996) in regard to how human being successful in discerning grouping scenes making up of surfaces, parts, and a whole systematically organized in mental procedure instead of the disorderly, energetic aggregation of zillions of nonidentical colors exhibited by human being's retinal receptors. He managed to explore this matter in question by finding out impetus features that brought about fundamental formation of elements to be discerned as well ordered in individual grouping scene. The features Wertheimer diagnosed are generally called the principles of grouping scene, such as proximity, common fate, good continuation, element connectedness and common region and so on. In one and all principles of grouping scene, elements who share a close interdependence in regard to the specified characteristics and qualities incline to be categorized together. More precisely, those specified characteristics and qualities pertaining to unit grouping may be set isolated and concluded to a larger unit, however, they are not utterly deprived of their distinctiveness in a larger unit (Sasaki, 2007). Due to these researches' scope, the conceptual model and theoretical framework of gestalt perception is therefore a promising paradigm to take stock of what we can explore about gestalt image transmission of perceptual organization in Chinese literary translation and how our understanding of translators' conceptual mental experience of image-G transmission in Chinese literary translation through their cognitive processing.

\section{Gestalt Perception and Gestalt Perception Laws}

The organization of gestalt perceptual provides clues to that psychophysical field and isomorphism have an overwhelming impact on various gestalt perception laws. They are the law of closure, the law of good continuation, the law of proximity and the law of similarity respectively (Koffka, 1996). These laws are actually all being functionally equal and the utility of their patterns can be considered as representation of closely-related spatial form contributing to conceptual content concerned. Among which, law of continuity and law of closure are the core and elementary tenets. Law of closure conveys the indication of continual tendency and is a precondition for good continuation requirements and perceptual boundary conditions, which in turn provides a conceptual integration network for law of closure in the form of cognitively representable frame (Koffka, 
1999). The other gestalt perception laws are mainly derived from these two laws and are particular secondary reference forms of them (Pomerantz \& Kubovy, 1986). Representations of laws of closure and good continuation display a trend to attain the utmost degree of uniformity with the minimum disbursement of cognitive endeavour carried out by human being's perceptual operation.

Gestalt psychology scholars hold that gestalt perception laws are not only cope with perception alone but also can be adopted as cognitive instrument for cognitive perceptual-related and gestalt mental-concerned studies. Based on holistic mechanistic pattern of conceptual archetypes, gestalt perception laws may provide the conceptual model and theoretical framework for the multidimensional research on cognitive science study on account of furnishing a tentative, exploratory and comprehensive implementation to such kind of studies (Kubovy \& van den Berg, 2008). By taking the mutual interdependence relations between gestalt perception and gestalt mental-concerned studies into consideration, it is feasible to obtain much more general truth towards that direction. Above all, it seems to be easily accessible to figure out a quintessential feature of perception organization that goes beyond the composition of gestalt grouping and the recognition of their representing scheme by correlating them with analogous gestalt mental-concerned studies. To be specific, during the mental processing of image-G transmission in literary translation, there is an intersubjectively cogent institution of image-G rearrangement principles which allows integrating, organizing, contrasting, and processing of image-G embedded or re-embedded within a specified literary contextual discourse. Therefore, image-G in literary translation has certain tangible implication which, anyhow, is not dissociated from or spatially or inferential prior to the composition of literary discourse, As we have explored in the case of cognitive linguistic application, those gestalt perception law is conventional in broadest respects that, in the discourse of literary context mentioned above, they can be applied to image-G transmission in literary translation, and image-G transmission can be put in effect independently in the similar cognition pattern or the engendering gestalt. Since both patterns pertain to the same gestalt perception, they reflect that gestalt mental-concerned studies when one could be transformed into the other, and conversely, by some transformation from the grouping associated with the gestalt.

\section{The Application of Gestalt Perception Laws to Image-G Transmission in Literary Translation}

\subsection{Law of Closure}

The definition of law of closure is that congruous cognitive elements tend to be grouped into complete structures. The designation of law of closure is originated by Wertheimer (1996). It is regarded as one of the fundamental organization laws of gestalt perception, involving aspects of visual organization, psychological recognition as well as mental perception. From the perspective of visual perception, it possesses a predisposition to surround a circle by completing a outline 


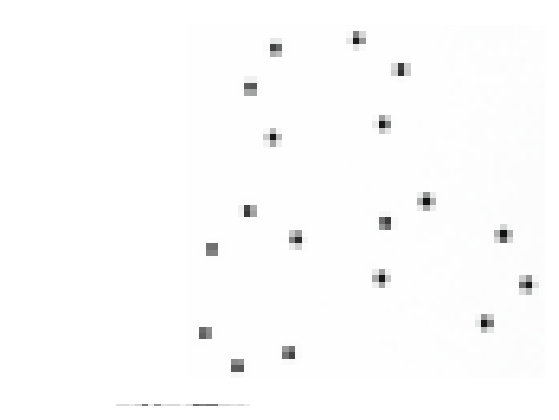

Figure 1. Law of closure (Wertheimer, 1996: p. 176).

and eliding separation line in the silhouette. On a deeper level, defective wholes, which are embedded in forms of observance, conception, presumption memories and active deed and so on, are also prone to shape a subjective enclosure of integrated configuration. In Figure 1, it is can be perceived that those ink spots, who look in congruous in succession with each other, tend to be appeared into three complete circular tracks. Despite they are actually incomplete fragments of real circular tracks, the separated variables in accommodated resembling of distinction segments can be recognized as a dynamic circuit presented at each dot in perceptual model. The conceptualization of law of closure which would take account of more than solely psychological studies within the exclusively psychological frame (Stahl \& Wang, 2008). The concept is explored further in Restle's concept of "motion configuration". He emphasizes the closure aspect of the motion configuration which his study applies, indicating that an uninterrupted frame system of intellectually interrelated imagery groupings, is brought into play, is triggered, wherever psychological frame of imagery coherence actualization can be achieved based on the formulation of a series of theme-concerned imagery components (Restle, 1979). The gestalt principles applies not to the theoretical frame of idealities, but is rather a notion which, in a similar manner of causation, is essential for the fields of the real. "To apply the category of cause and effect means to find out which parts of nature stand in this relation. Similarly, to apply the gestalt category means to find out which parts of nature belong as parts to functional wholes, to discover their position in these wholes, their degree of relative independence, and their articulation of larger wholes into sub-wholes" (Kosslyn \& Julesz, 1998: p. 125).

In that sense, it is reasonable to introduce law of closure into image- $G$ transmission in literary translation. As S-text and T-text vary in their psycho-linguistic constructivism, the holistic image-G units entity in literary discourse is not originated from translators' comprehension procedures for imagery's lexical combination, rather, that of their conceptual implicit association for imagery's cognitive context-based amalgamation. In fact, imagery's lexical combination cannot incontrovertible keep possession of and even misrepresent the integrity of gestalt quality and aesthetic theme. To be precise, target readers' conceptual associative thinking about dotted imagery amalgamation in literary discourse will help conform the scattered imagery elements systematically into gestalt imagery 
whole in T-text, and new image-G whole in T-text can be harmoniously consolidated and conceptually enclosed. That is, aesthetically gestalt theme is mental actualized while actualization stains in T-text is based on the closure nature of dotted imagery. Inspired by dotted imagery's holistic scene and imaginative impression, target readers will be able to produced gestalt imagery whole in the interpretation of T-text, which is not just confined by the dotted imagery in original literary works. Take an example from the translation of Yan Jidao's writings Riverside Daffodils (晏几道《临江仙》):

梦后楼台高锁, 酒醒帘幕低垂。

menghou loutai gaosuo, jiuxing lianmu dichui.

去年春恨却来时。

qunian chunhen que laishi.

落花人独立, 微雨燕双飞。

luohua ren duli, weiyu yan shuangfei.

记得小苹初见, 两重心字罗衣。

jide xiaoping chujian, liangchong xinzi luoyi.

琵琶弦上说相思。

pipa xianshang shuo xiangsi.

当时明月在，曾照彩云归。

dangshi mingyue zai, cengzhao caiyun gui.

"Awaking from a dream in the locked pavilion,

I sober up to see the curtain hanging low.

Last spring's grief again assail me.

A midst the falling flowers she stood alone,

While in the light drizzle, pairs of swallows played.

I recall my first encounter with Xiao Pin,

She wore a light silk dress, embroidered with two hearts.

The music of her lute expressed her tender feeling.

Though the bright moon still shines,

The same moon sent away the rosy cloud."

(Translated by Xu Yuanchong)

In general, from the perspective of law of closure, there are three groupings of dot-related imagery in this Chinese Song lyric. The first imagery grouping includes the images of loutai "pavilion", lianmu "curtain", caixia "rosy cloud" and mingyue "moon", which are spatially interrelated with each other: lianmu "curtain" is a shade of seat by loutai "pavilion", which in turn beetles over lianmu "curtain"; mingyue "moon" and caixia "rosy cloud" are perfectly set each other off. The most notable locality of their spatial scene is that these four with crossly intersecting relation are located in different lines in this poetry discourse. Thus it can inspire target readers to mentally actualize holistic scene and continuously enclosure gestalt essence in the theme construction of complete gestalt image. 
The second imagery grouping involves the images of luohua "falling flowers", weiyu "light drizzle", caixia "rosy cloud" and mingyue "moon", each of whom is natural phenomenon with a entity-interrelated nature of its own. Thus the holistic imagery grouping creates an artistic gestalt atmosphere of clear wildness and empty thinness. The third imagery grouping includes time concepts of jide "recall", qunian "last spring" and dangshi "at that time", which contain similarity of time attributes. A series of time imagery induce target readers to experience the poet's sweet-bitter memories of pleasant days he had with Xiao Pin. All the reminiscence can be chained together to complete an enclosure story, whose chronologically coherent sequence endows theme-concerned gestalt image with wistful sentimentality. The application of law of closure to image-G transmission in this Chinese Song lyric does represent complex combinatorial optimization of individual images. The combinatorial imagery optimization is set free from the constrain by a single sentence or line, rather, each line implies certain gestalt connection with the other lines, rather than being isolated in its own imagery.

\subsection{Law of Good Continuity}

The another principal grouping principle of gestalt perceptual organization is law of good continuity, which is a reference denoting a tendency for language, sonic and image stimulus received by human brain to be conceptually categorized to construct smooth contours (Wertheimer, 1996). Its definition is that congruous cognitive elements tend to be structured so as to minimize discontinuity. Law of good continuity is deeply convinced that the sum of continuous contour to some degree with adjacent fellows is much more sophisticated and enriching than that of discontinuous or asymmetric contours. In congruous cognitive elements who are being in agreement, harmony and correspondence with each other are easy to be perceptually organized in order to pare down disconnectedness and irregular variation. As shown in Figure 2, the figure above is always apprehended as the crisscrossing of two winding and tortuous lines, rather than four unconnected lines made of six to eight dots or a collection of separate dots on a blank background.

A quite productive approach for researching into the law of good continuity in dotted images was proposed by Field, Hayes and Hess (1993). In this approach, a contour organized from circumscribing situated dotted images is implanted in a unsystematic scope of correspondingly dispersed interfering images, so as to completely remove or get rid of the role of proximity (Lowe, 1985). Banding the dot-

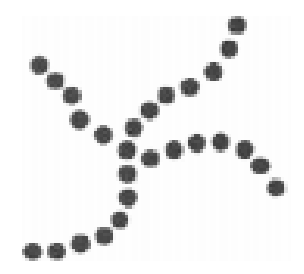

Figure 2. Law of good continuity (Wertheimer, 1996: p. 182). 
ted image divergently together with the contour whole makes the contour to be effortlessly perceived, whereas employing random selection or sampling in the positioning of image elements makes the contour whole unnoticeable, evidently indicating the role of good continuity is almost separate from proximity. These findings led Field, Hayes and Hess to imply that the mental perception of an association background which regulates the bonding of oriented elements within a circumscribed perceptible neighborhood, a formulation that is closely allied with the organization of co-circularity assist neighborhoods, expanded previously for the intention of contour perfection in computer vision (Parent \& Zucker, 1989).

Researches on the law of good continuity from the perspective of ecology have also came out since the late twentieth century. Kruger (1998) and then Sigman et al. (2001) proved confirmation of collinearity, cocircularity, and parallelism in the data of natural images. Geisler, Perry, Super, and Gallogly (2001) obtained alike findings by adopting both categorized and uncategorized natural image data, in fairly close correspondence with the turning of human perception to the good continuity cue. Geisler et al. regarded contours as ordered sets of oriented segments, evaluating the data for a set of contour segments on a regular object background, irrespective of whether these segment sets were close together or separated apart on the object background. Strikingly, Elder and Goldberg (2002) devised representation of contours as coherent succession of oriented segments along the contours. The probability quantitative percentage of two oriented segments on the same object background is of much more considerable size for the successive data, demonstrating a much more significant statistical interaction between neighboring contour segments (Machilsen, Pauwels, \& Wagemans, 2009). As we mentioned above, it is widely agreed that law of good continuity can be applied to perceptual and cognitive researches of images organization in various fields. There is likewise nothing surprising about probing into gestalt image transmission in literary translation and having an important place in a comprehensive account of target readers' conceptual organization of image-G embracing its acquisition, analysis and construction. Take an example from the translation of Qin Guan's writings Courtyard Full of Fragrance (秦观《满庭芳》):

山抹微云, 天连衰草, 画角声断谯门。

shanmo weiyun, tianlian shuaicao, huajiao shengduan qiaomen.

暂停征棹, 聊共引离尊。

zanting zhengzhao, liaogong yin lizun.

多少蓬莱旧事, 空回首、烟䨠纷纷。

duoshao penglai jiushi, kong huishou, yanai fenfen.

斜阳外，寒鸦万点，流水绕孤村。

xieyang wai, hanya wandian, liushui rao guchun.

消魂当此际, 香囊暗解, 罗带轻分。

xiaohun dang ciji, xiangnang anjie, luodai qingfen.

谩赢得青楼薄幸名存, 此去何时见也?

man yingde qinglou boxing mingcun, ciqu heshi jianye? 
襟袖上, 空惹啼痕。

jinxiu shang, kongre tihen.

伤情处, 高城望断, 灯火已黄昏。

shangqing chu, gaocheng wangduan, denghuo yi huanghun.

\author{
"A belt of clouds grids mountains high \\ And withered grass spreads to the sky, \\ The painted horn at the watchtower blows. \\ Before my boat sails up, \\ Let's drink a farewell cup. \\ How many things do I recall in bygone days \\ All lost in mist and haze! \\ Beyond the setting sun I see but dots of crows \\ And that around a lonely village water flows. \\ I'd call to mind the soul-consuming hour \\ When I took off your perfume purse unseen \\ And loosened your silk girdle in your bower. \\ All this has merely won me in the Mansion Green \\ The name of fickle lover. \\ Now I'm a rover, \\ Oh, when can I see you again? \\ My tears are shed in vain; \\ In vain they wet my sleeves. \\ It grieves \\ My heart to find your bower out of sight; \\ It's lost in dusk in city light." \\ (Translated by Xu Yuanchong)
}

The imagery in the poetry received by target readers' brain is to be conceptually categorized to construct three smooth contours, namely, the upper contour, the intermediate contour and the lower contour. The upper contour involves the contour segmental images of weuyun "a belt of clouds", shan "mountains", tian "sky" and xieyang "setting sun", which distribute segment sets of imagery data in upper subspace within the object background of spatial coordination. The intermediate contour involves the contour segmental images of zhengzhao "sials up boat", yanai "mist and haze", hanya "dots of crows" and gucheng "a lonely village", which distribute segment sets of imagery data in intermediate subspace within the object background of spatial coordination. The lower contour involves the contour segmental images of shuaicao "withered grass", liushui "water flows", which distribute segment sets of imagery data in lower subspace within the object background of spatial coordination. Though their conceptual content is generally not quite schematic, these images constitute a new characterization on category morphism of good spatial continuity. From this characterization, target readers can mentally capture the spatial position of 
segment imagery sets within a circumscribed perceptible neighborhood that motivated smooth contours of the classic transformational frame of the poetry, rather than proposed as the schematic assimilation of possessive compositions. In addition, the contour segmental images of jiushi "bygone days", huishou "recall", ciji "at this instant" and heshi "when will it come" can be conceptually linked by target readers as a sum of smooth continuous contour in their time order and logical relation. Although their semantics cannot be allowed to cover all of the possible interpretations of temporal length, they are more or less compatible with similar conceptualizations of continuous sequence. These congruous cognitive elements who are being in continuous correspondence with each other serve to characterize attendant logical-related flows for which it is much more closely associated with target readers' communicative relevance. That is, what is required is that it may recall shifting movement in time from present to past and back again as functional, symmetrical, iconic sequencing neighboring contour segments. In terms of conceptual integration, it embodies time-order good continuity and logical whole-part good continuity within composition, completion and elaboration of target readers' stream of consciousness which can arouse them to construal and embrace image- $\mathrm{G}$ acquisition, analysis and construction in literary translation.

This proportionate characterization for target readers' conceptual rationalization is directly invoking their instinctual insight of a methodologically good continuity cue. During their mental interpretation of the poetry, their conceptualization shares the cognitive communicative function of expanding gradually out into the representation of coherent contours in good continuity succession of oriented segments imagery along the contours and casting their eyes to the horizontal tremendous spaciousness scenery depicted in the poetry. Target readers' subjective perception seems to obstruct a systematic denotation of gestalt concept in good continuity succession of oriented segments imagery along its contours. However, by referring to the resemblance proliferation of harmonious autumn landscape imagery, their attempt to capture the corresponding gestalt properties as the sense of sorrow and plaintive atmosphere in the contour's mathematical framework which is not be able to exceed their intuitive construction (Mohan \& Nevatia, 1992). In sum, target readers' cognitive perception of segments imagery on a specific contextual contour plays a significant role in invoking their conceived entity as reference point for purposes of establishing mental contact with image-G qualities as well as perceiving gestalt on good continuity contour of image-G transmission in literary translation. The application of law of good continuity to image-G transmission in literary translation does correlate with the contour grouping of imagery with respect to various aspects in contextual discourse, such as space, time, logic and cognition. Such kind of aspects do exist, although mentally constructed, they do exert remarkable effect, and they seems to represent the conceptual acceptability of a reciprocal correlation with successive images. Since oriented segmental images are delimited upon the contextual-frame background, the dimension and manifestation of contextual-frame 
background can be operated as instruction by target readers to obtain essences of gestalt imagery in S-text, which could be taken into consideration to assume intended conceptualization when target readers' psychological sophistication and significance of the contour background is varied.

\subsection{Law of Similarity}

The definition of law of similarity is that a series of cognitive stimulus who are being in agreement, harmony, or correspondence with each other are prone to be conceptually organized in alliance. These cognitive elements with similar qualities and characteristics like volume, colour, configuration or height are perceived by human brain as components of the corresponding contour. It could be remarked that the law of similarity maintains also for sensory association. "Maintaining a constant interval, the beats may be soft and loud" (Wertheimer, 1996). Since there is an alternative account which possesses the analogy while cognitive stimulus are similar in which they are characteristically adjacent to each other, the law of proximity could be regarded as a subordinate classification of the law of similarity. As shown in Figure 3, the following set of open dots in the figure above is generally conditioning-reflex organized as four perpendicular pillars consisting of two black solid lines and two white hollow lines respectively rather than, that is, several parallel lines checkered with mixed black solid dots and white hollow dots. It is obvious that the integration of dozens of dots in the background contour are conceptually constructed in terms of identical correspondences of color and shape.

In general, the law of similarity emphasizes that segments with alike properties are much more likely to be united than segments who are dissimilar to each other in qualities concerned, which has been confirmed in the amount of instances like the four perpendicular pillars explored above. For objected segments in specific contours, researches have commonly proved a reduction in contour construction operation for dissimilar properties in given situation (Feldman, 2007). Yet, it not for those, who contain embedded interrelation with other categorization intimation such as proximity and good continuity. Elder and Goldberg (2002) surveyed the ecological data of similarity in outlines, and found that the brightness cue bears much more functional details for contour construction whereas the contrast cue is to a sets of segments of the mutual opposition, Geisler and Perry (2009) have more recently studied the ecological statistics of contrast mutual opposition, demonstrating that it is also an enlightening cue for contour integration. By adopting the law of similarity into image-G transmission in literary translation,

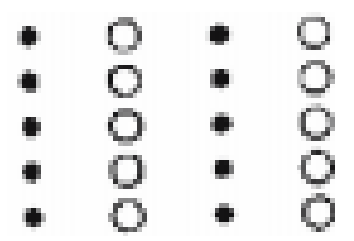

Figure 3. Law of similarity (Wertheimer, 1996: p. 189). 
target readers can operate cognitively within that theoretical function, which allows them to successfully filter out an extension of modifications and interference fitting into unpacking conceptual organization in literary discourse and appreciate the most core content of image-G essence in contextual prominence. The cognitive characteristics can make people grasp the inherently core elements in the complex. Take an example from the translation of Su Shi's writings Water Dragon's Chant (苏轿《水龙吟》):

似花还似非花，也无人惜从教隹。

sihua haisi feihua, ye wuren xicong jiaozhui.

抛家傍路，思量却是，无情有思。

paojia banglu, siliang qieshi, wuqing yousi.

索损柔肠，困酣娇眼，欲开还闭。

yingsun rouchang, kunhan jiaoyan, yukai huanbi.

梦随风万里, 寻郎去处, 又还被蒀呼起。

meng suifeng wanli, xunlang quchu, youhuai beiying huqi.

不恨此花飞尽, 恨西园、落红难缀。

buhen cihua feijin, hen xiyuan、 luohong nanzhui.

晓来雨过，遗踪何在？一池萍碎。

xiaolai yuguo, yizong hezai? yichi pingsui.

春色三分, 二分尘土, 一分流水。

chunse sanfen, er'fen chentu, yifen liushui.

细看来, 不是杨花点点, 是离人泪。

xikan lai, bushi yanghua diandian, shi liren lei.

"They seem to be and not to be flowers;

None pity them when they fall down in showers.

Forsaking leafy home,

By the roadside they roam.

I think they are fickle but they have sorrow deep.

Their grief o'er-laden bowels tender

Like willow branches slender,

Their wistful eyes, like willow leaves, near shut with sleep,

About to open, yet soon closed again.

They dream of drifting with the wind for long,

Long miles to find a tender-hearted man,

But are aroused by the orioles' song.

I do not grieve willow catkins have flown away,

But that in Western Garden the fallen petals red

Cannot be gathered. When dawns the day

And rain is o'er, we cannot find their traces

But in a pond with broken duckweeds overspread.

Of spring's three graces,

Two have gone with the roadside dust 
And one with the waves. But if you just

Take a close look, you will never

Find willow down but tears of those who sever,

Which drop by drop

Fall without stop."

(Translated by W. J. Fletche)

The images of luohong "fallen petals red", liushui "waves", yanghua "petals drop by drop" and huafeijin "willion catkins flown away" have got certain similar features in common, of whom are in dynamic condition similar to others employed in this poetry. By speculating on these natural scenery images of dynamic descend state, target readers can perceive corresponding untapped gestalt imagery referring to wistful emotions as it has been implicated in this poetry. Petals are faded and fallen in the late autumn, as the lady has numerous sad thoughts, which are inadvertently scattered across and set her mind wandering. The images of rouchang "bowels tender", jiaoyan "wisful eyes" and pingsui "duckweeds overspread" have traced a close analogy with each other, of whom possess softness and delicateness qualities as well as characteristics similar to others employed in this poetry. There are normally possible commensurable mental images aroused by target readers that correspond to these images of exceedingly inextricable and commiserative sentimental emotions. This is even true for the relevance degree of images with certain similar sentiment and affection, such as the images of buhen "grieve not", yousi "tossing and turning" and siliang "thinking carefully", for their mental image is conceived of gestalt theme as deep sorrow and depressing loss in the pictorial depiction. Any particular gestalt imagery is supposed to be force image presentation which can be derived from close analogous mental images.

From three-dimensional angles in space, time and psychic aspects, this poetry is organized by interlaced and scattered image clues with certain similar features in common. These particular and fleshy image clues mentally perceived by target readers in this poetry bring to a light to plentiful and vivid artistic feature and gestalt essence. Furthermore, target readers are disposed to organize alike image schema and consciously accommodated with the author to become cognizant of the author's own genuine and sincere emotions which provoked strong surges of nostalgia for the days of yore. It is a conventional pattern that one scattered image is represented semantically with other paralleled image clues. However, clustering of this sort should have a functional counterpart in the original contextual discourse, not only of general modality patterns, but also of the manifested environmental cognition those patterns tend to be conceptualized by target readers in their holistic perception. The application of gestalt perception law of similarity to image-G transmission in literary translation goes with conceptual experience of functional paralleled image in the sequence of target readers' underlying physiological cross-space mapping model. Therefore, it is reasonable to arrive at the proposition that the semantic parameters of interlaced and scattered 
image clues with certain similar features are always structurally identical with a functional order in the sequence of target readers' conceptual processes.

\subsection{Law of Proximity}

Wertheimer (1996) claimed that segments who are in closer proximity with each other are always be conceptually discerned by human being as a systematic contour. The definition of law of proximity (Figure 4) is that congruous cognitive elements that are spatially close together tend to be structured as a group. It emphasizes that ultimate constituent of a contour between several segments heightens as all of them are in the neighbourhood at close quarters, A sum of studies are intended to capture how the complementary role of a heighten systematic contour play as a principle of compositionality in neighbour segments' differentiation. Generally speaking, Oyama (1961) proved that this interconnection could be precisely addressed and characterized as a power law, for the power-distribution is that of a systematic contour which circulates through an inviolate collective unity of a certain concept has decoupled influence upon its distribution. In contrast with Oyama's study, Kubovy, Holcombe and Wagemans (1995) chose to adopt a logarithm configuration which is compatible with discrete backward grouping of contour functioning (Mumford, 1992; Williams \& Jacobs, 1997). Nevertheless, Kubovy, Holcombe and Wagemans (1995) also indicated that a power law configuration is almost identically congruous to their statistic of functional effects. In addition, they declared that a variety of proximity segments was in the vicinity of a relative extent in remaining quantity and this is evident, say, ratio of notation in which the tailored successive positions of factorial function under similar parameters did not exert influence on results (Arnheim, 1967). Due to the fact that the power law has been regarded as desired scale invariant distribution, their findings provide assertive evidence to the power law configuration of proximity, which has been adopted in following auditory organization studies (Claessens \& Wagemans, 2008).

Proceeding from the boundary condition about ecological distribution follows a power law, perceptual scale invariance is conceptually analytical owing to that the proximity of segments in material contours of concrete images is also scale invariant. In accordance with this argument, Sigman, Cecchi, Gilbert, and Magnasco (2001) demonstrated that a law related to dynamic force exerts its curative effects by sieving and decontaminating the spatial dimension through the production of impulse digital filter to natural images. Anyhow, quantitatively ana-

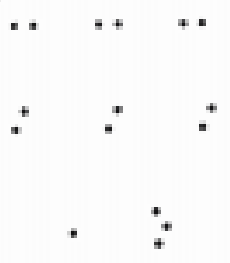

Figure 4. Law of proximity (Wertheimer, 1996: p. 195). 
lyzed studies of the correlation between psychophysics and ecological data are quite embracing. Oyama, Simizu, and Tozawa (1999) roughly calculated that the perceptual law related to dynamic force used to pare down its nearest forthcoming and the most substandard segments in contour configuration. In addition, Sigman et al. did not constrain their quantification to sets of contiguous segments in the shifting balance of schema-forming image contours. As a matter of fact, the quantification were not confined to be on the identical schema-forming configuration, or even on specific configuration at all, achieving at a combination of powerfully associated and just poorly associated image characteristics. Elder and Goldberg (2002) precisely illustrated how the segmental content of image contours is to be taken its distributing force, requiring conceptually recognition to categorize the concatenation of segments structuring the contours of natural images, with the aid of a mutual-influencing image modifying implement. This affective implement made the quantification to be confined to succeeding segments within the identical configuration and relinquished the force law with responded segmental, which was quite similar to Oyama's findings. Whether this segments is spatially unattached with orientation in the contour configuration or not remains a meaningful open question, although psychophysical statistics (Claessens \& Wagemans, 2008) suggested that at least it may vary since psychological factors function as a drive towards regularity of contours. In conclusion, the converging points between psychophysics and ecological data are convincing. Proximity segments in ecological scale are indeed operated by a power law and manifest scale invariance, of which possessions are reflected by the regularized pattern (Jacobs, 2003). Thus, it is reasonable to get a hint that the law of proximity is a promising application for proximate gestalt statistic segments of image-G transmission in literary translation scenes during target readers' perceptual processes. Take an example from the translation of Cao Zhi's writings The Fair Maiden (曹植《美女篇》):

美女妖且闲, 采桑歧路间。

meinv yao qie xian, caisang qilu jian.

柔条纷申冉, 叶落何翩翩!

routiao fen ranran, yeluo he pianpian!

攘袖见素手, 皓腕约金环。

rangxiu jian sushou, haowan yue jinhuan.

头上金爵钗, 腰佩翠琅玕。

toushang jin juechai, yaopei cui langgan.

明珠交玉体, 珊瑚间木难。

mingzhu jiao yuti, shanhu jian munan.

罗衣何飘摇, 轻裾随风还。

luoyi he piaoyao, qingju sui fenghuan.

顾盼遗光彩, 长啸气若兰。

guanpan yi guangcai, changxiao qi ruolan.

行徒用息驾, 休者以忘餐。 
xingtu yong xijia, xiuzhe yi wangcan.

借问女安居？乃在城南端。

jiewen nv anju? naizai cheng nanduan.

青楼临大路, 高门结重关。

qinglou lin dalu, gaomen jie chongguan.

容华耀朝日, 谁不希令颜?

ronghua yao zhaori, shuibu xi lingyan?

媒氏何所营？玉帛不时安。

meishi hesuo ying? Yubo bushi an.

佳人慕高义, 求贤良独难。

jiaren mu gaoyi, qiu xianliang dunan.

众人徒嗷嗷, 安知彼所观。

zhongren tu aoao, anzhi bi suoguan.

盛年处房室, 中夜起长叹。

shengnian chu fangshi, zhongye qi changtan.

"A maiden fair is full of charm and grace.

She gathers mulberry leaves at crisscross place.

The tender branches rustle one and all;

How many mulberry leaves moan and fall!

Her arms so white are seen with sleeves uprolled;

Around her wrist a bracelet made of gold.

A golden sparrow pin adorns her hair;

A green jade pendant hangs at her waist fair.

Her lovely form encompassed with pearls bright

And carol and blue glass beads left and right.

How do her silken dresses flow with gentle breeze!

Her melting glance reveals her shining eye;

In her sweet breath you hear the orchid sigh.

The travelers en route would halt their car;

Those resting would forget where their meals are.

If you ask where is her house renown,

It stands at the southern end of the town.

Her house by the highway has floor on floor;

It's green with high gate and double door.

She looks as radiant as the morning sun.

Who'd not admire such a beautiful one?

Why are the busy go-between delayed?

Where are betrothal gifts of silk and jade?

The maiden fair longs for a worthy mate;

It's hard to find one, so she has to wait.

People in vain may gossip a great deal.

What do they know of her lofty ideal? 
She lives alone at her prime, fair and bright.

How can she not sigh at dead of night?"

(Translated by Xu Yuanchong)

The poetry gives a detailed portrait of a beauty who plucks mulberry leaves by the roadside. A series of proximity segmental images are adopted to be comprehended almost lifelike in her appearance, expression, dress, personal adornment and bearing. To be specific, the images of sushou "white arms", haowan "snow-like wrist" and yuti "lovely from" have certain closer proximity with each other in color and body parts. By conceptualizing psychological associative scene of these proximal properties in images mentioned above, target readers are enlightened to the beauty's flawless pale skin, which presents the identical configuration of gestalt imagery about pure sincere genuine unsophisticated of a endowed heavenly beauty. The images of jinhuan "a bracelet made of gold", jinjuechai "a golden sparrow pin", cui langgan "a green jade pendant", mingzhu "bright pearls" and shanhu "carol and blue glass" have certain closer proximity with each other in the beauty's fine ornamentation and jeweled ornaments. By conceptualizing psychological associative scene of these proximal properties in images mentioned above, target readers are enlightened to a well-groomed beauty, which presents the identical configuration of gestalt imagery about elegant demeanour of a graceful, secluded and sparkling dazzling lady. The images of luoyi "silken dresses", qingju "light skirt", piaopiao "flow with ease", shuifeng huan "flutter with gentle breeze", qingju "light skirt", ranran "rustle one and all" and pianpian "moan and fall" have certain closer proximity with each other in the beauty's flowing garments and decent poise. By conceptualizing psychological associative scene of these proximal properties in images mentioned above, target readers are enlightened to the beauty's unique radiance and temperament, which presents the identical configuration of gestalt imagery about dignified bearing and elegant carriage of a demure and dainty lady. The images of gupan "melting glance", changxiao "the orchid sigh", guangcai "shining eyes" and ruolan "sweet breath" have certain closer proximity with each other in expression looks and body movements. By conceptualizing psychological associative scene of these proximal properties in images mentioned above, target readers are enlightened to the fond gazing of the beauty and a look of quick intelligence and soft refinement in her eyes, which presents the identical configuration of gestalt imagery about unsophisticated sincere and genuine vitality of the beauty who are drawn in high spirits. The application of gestalt perception law of proximity to image- $G$ transmission in literary translation goes with conceptual comprehension of a series of images with adjacent nearness and closeness in the sequence of target readers' underlying physiological blending-space mapping model.

\section{Conclusion}

The article makes an analysis of image-G transmission in Chinese literary translation based on the application of gestalt perception laws. With a brief review of 
gestalt perception, the study first investigates the gestalt perception both as an inbred conceptual faculty and as a contour-grouping instruction for image-G transmission. The study then elucidates the essentials of gestalt perception laws of image-G transmission in Chinese literary translation, which are illustrated by given examples. It finally explores translators' conceptual interaction and mental processing in image- $G$ transmission. It could be concluded that image-G transmission in Chinese literary translation is not just an abstract semantic process, but also should be understood as a conceptual mentalistic experience, which is more elementary than both concrete categories and abstract principle. The research results can provide practical hints and applicative guidance to translators' self-awareness of their conceptual mental construction of image-G transmission in Chinese literary translation.

\section{References}

Arnheim, R. (1967). Art and Visual Perception. Berkeley: University of California Press.

Claessens, P. M. E., \& Wagemans, J. (2008). Perceptual Groupings in Gabor Lattices: Proximity and Alignment. Perception \& Psychophysics, 67, 1446-1459. https://doi.org/10.3758/BF03193649

Elder, J. H., \& Goldberg, R. M. (2002). Ecological Statistics of Gestalt Laws for the Perceptual Organization of Contours. Journal of Vision, 2, 324-353. https://doi.org/10.1167/2.4.5

Feldman, J. (2007). Formation of Visual "Objects" in the Early Computation of Special Relations. Perception \& Psychophysics, 69, 816-827. https://doi.org/10.3758/BF03193781

Field, D. J., Hayes, A., \& Hess, R. F. (1993). Contour Integration by the Human Visual System: Evidence for a Local “Association Field.” Vision Research, 33, 173-193. https://doi.org/10.1016/0042-6989(93)90156-Q

Geisler, W. S., \& Perry, J.S. (2009). Contour Statistics in Natural Images: Grouping across Occlusions. Visual Neuroscience, 26, 109-123. https://doi.org/10.1017/S0952523808080875

Geisler, W. S., Perry, J. S., Super, B. J., \& Gallogly, D. P. (2001). Edge Co-Occurrence in Natural Images Predicts Contour Grouping Performance. Vision Research, 41, 711-724. https://doi.org/10.1016/S0042-6989(00)00277-7

Jacobs, D.W. (2003). What Makes Viewpoint-Invariant Properties Perceptually Salient? Journal of the Optical Society of America A: Optics, Image Science, and Vision, 20, 1304-1320. https://doi.org/10.1364/JOSAA.20.001304

Koffka, K. (1996). Perception: An Introduction to the "Gestalt-Theorie". Psychological Bulletin, 19, 531-585. https://doi.org/10.1037/h0072422

Koffka, K. (1999). Principles of Gestalt Psychology. London: Lund Humphries.

Kosslyn, D. A. \& Julesz, T. (1998). Visual Images Preserve Metric Spatial Information: Psychophysical Description of Studies from Image Scanning. Journal of Human Psychology: Human Perception and Conceptualization, 8, 56-65.

Kruger, N. (1998). Collinearity and Parallelism Are Statistically Significant Second Order Relations of Complex Cell Responses. Neural Processing Letters, 8, 117-129. https://doi.org/10.1023/A:1009688428205

Kubovy, M., \& van den Berg, M. (2008). The Whole Is Equal to the Sum of Its Part: A 
Probabilistic Model of Grouping by Proximity and Similarity in Regular Patterns. Psychological Review, 115, 131-154. https://doi.org/10.1037/0033-295X.115.1.131

Kubovy, M., Holcombe, A. O., \& Wagemans, J. (1995). On the Lawfulness of Grouping by Proximity. Cognitive Psychology, 35, 71-98. https://doi.org/10.1006/cogp.1997.0673

Lowe, D. G. (1985). Perceptual Organization and Visual Recognition. Boston, MA: Kluwer. https://doi.org/10.1007/978-1-4613-2551-2

Machilsen, B., Pauwels, M., \& Wagemans, J. (2009). The Role of Vertical Mirror Symmetry in Visual Shape Detection. Journal of Vision, 9, Article 11.

https://doi.org/10.1167/9.12.11

Mohan, R., \& Nevatia, R. (1992). Perceptual Organization for Scene Segmentation and Description. IEEE Transactions on Pattern Analysis and Machine Intelligence, 14, 616-635. https://doi.org/10.1109/34.141553

Mumford, D. (1992). On the Computational Architecture of the Neocortex: II. The Role of Cortico-Cortical Loops. Biological Cybernertics, 66, 241-251. https://doi.org/10.1007/BF00198477

Oyama, T. (1961). Perceptual Grouping as a Function of Proximity. Perceptual and Motor Skills, 13, 305-306. https://doi.org/10.2466/pms.1961.13.3.305

Oyama, T., Simizu, M., \& Tozawa, J. (1999). Effects of Similarity on Apparent Motion and Perceptual Grouping. Perception, 28, 739-748. https://doi.org/10.1068/p2799

Parent, P., \& Zucker, S. W. (1989). Trace Inference, Curvature Consistency, and Curve Detection. IEEE Transactions on Pattern Analysis and Machine Intelligence, 11, 823-839. https://doi.org/10.1109/34.31445

Pinna, B. C. (2009). New Gestalt Principles of Perceptual Organization: An Extension from Grouping to Shape and Meaning. Gestalt Theory-An International Multidisciplinary Journal, 32, 26-65.

Pomerantz, J. R., \& Kubovy, M. (1986). Theoretical Approaches to Perceptual Organization. In: K. R. Boff, L. Kaufman, \& J. P. Thomas (Eds.), Handbook of Perception and Human Performance, Vol. 2, Cognitive Processes and Performance (pp. 32-63). New York, NY: Wiley.

Restle, F. (1979). Coding Theory of the Perception of Motion Configurations. Psychological Review, 86, 1-24. https://doi.org/10.1037/0033-295X.86.1.1

Sasaki, Y. (2007). Processing Local Signals into Global Patterns. Current Opinion in Neurobiology, 17, 132-139. https://doi.org/10.1016/j.conb.2007.03.003

Sigman, M., Cecchi, G. A., Gilbert, C. D., \& Magnasco, M. O. (2001). On a Common Circle: Natural Scenes and Gestalt Rules. PNAS: Proceedings of the National Academy of Sciences, USA, 98, 1935-1940. https://doi.org/10.1073/pnas.98.4.1935

Stahl, J. S., \& Wang, S. (2008). Globally Optima Grouping for Symmetric Closed Boundaries by Combining Boundaries and Region Information. IEEE Translations on Pattern Analysis and Machine Intelligence, 30, 395-411. https://doi.org/10.1109/TPAMI.2007.1186

Wertheimer, M. D. (1996). Gestalt Theory. In: W. D. Ellis (Ed.), A Source Book of Gestalt Psychology (pp. 156-227). New York, NY: Humanities Press.

William, L. R., \& Jacobs, D. W. (1997). Stochastic Completion Fields: A Neural Model of Illusory Contour Shape and Salience. Neural Computation, 9, 837-858.

https://doi.org/10.1162/neco.1997.9.4.837 